\title{
DEVELOPMENT OF TSUNAMI INUNDATION EVALUATION METHOD CONSIDERING DAMAGE LEVEL OF SEAWALL
}

\author{
Katsumi Seki, Chuo University, seki-k.15e@g.chuo-u.ac.jp \\ Taro Arikawa, Chuo University, taro.arikawa.38d@g.chuo-u.ac.jp \\ Kenichiro Shimosako, National Institute of Maritime, Port and Aviation Technology, shimosako@pari.go.jp \\ Tomohiro Takagawa, National Institute of Maritime, Port and Aviation Technology, takagawa-t@pari.go.jp \\ Yu Chida, National Institute of Maritime, Port and Aviation Technology, chida-yu@pari.go.jp
}

\section{INTRODUCTION}

Against the huge tsunami with the subduction-zone earthquake, structures such as breakwater and seawall are constructed. The expected effects of these structures are to reduce the inundation depth and inundation area. In other words, if we estimate tsunami inundation using numerical simulation accurately, it is necessary to reflect the situation of these structures in the numerical models. However in the present technology, it is difficult to predict while to estimate and reflect the destruction process by earthquake and tsunami attack.

In this study, we assume that the damage level of structures are uncertain phenomenon and we develop that evaluated the tsunami inundation stochastically using Monte Carlo method.

\section{NUMERICAL MODEL}

The numerical simulator named STOC (Storm surge and Tsunami simulator in Oceans and Coastal areas) was developed by Port and Airport Research Institute (PARI). We chose the hydrostatic pressure approximation into the vertical direction model (STOC-ML). The calculation area covered a bay facing the Pacific Ocean in Japan. We assumed two situations of the structure's damage. One is the crown height of structures decreases at the ratio of uniformity. The other one is the structure collapsed in a damage rate. For the case of collapse, we calculated one hundred cases those were randomly set for each damage rate (Monte Carlo method). Figure- 1 shows the sample case on the collapse situation of the structures (damage rate $50 \%)$.

\section{NUMERICAL RESULTS}

Figure-2 shows the comparison of the maximum inundation depth. It can be seen that inundation area greatly varies depending on the damage rate of structures in particular inner part of the bay.

Figure- 3 shows the relationship between the damage rate and inundation situation with reference to the value of damage rate $100 \%$. Inundation area and inundation volume are reduced by the effect of structures, but inundation depth is increased by the influence of reflection from structures.

\section{CONCLUSION}

The purpose of this study is to clarify the effect of different protective facility damage levels on tsunami inundation. In this study, 942 cases with different seawall damage levels were performed. The results indicate that some areas exist where the maximum inundation height increases by around $30 \%$ and the beginning of inundation occurs about 2 min earlier than in the case with no seawall. On the other hand, the inundation area was almost covered in the case with no seawall.

\section{REFERENCES}

PIANC (2013): Tsunami Disaster in Ports due to the Great East Japan Earthquake, PIANC Special Publication, Appendix to Report, No.112-2010 (Mitigation of Tsunami Disasters in Ports).

Tomita T., K. Honda and T. Kakinuma (2007): Application of three-dimensional tsunami simulator to estimation of tsunami behavior around structures, Coastal Engineering 2006, pp.1677-1688.

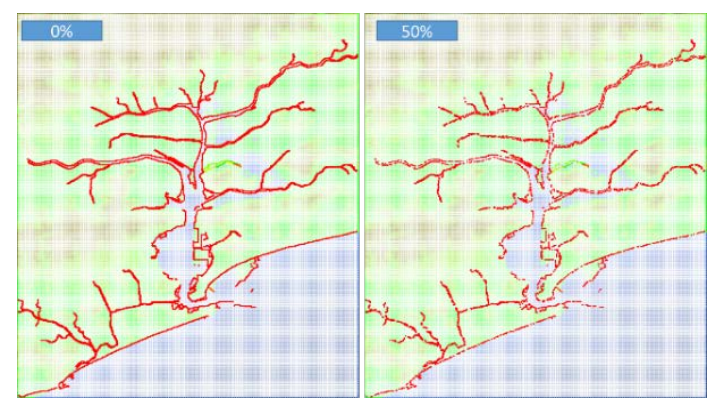

Figure-1. Sample of the Structure Condition

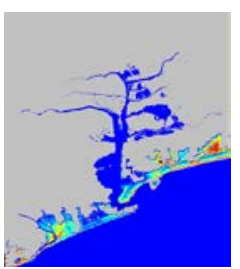

(a) Damage 0\%

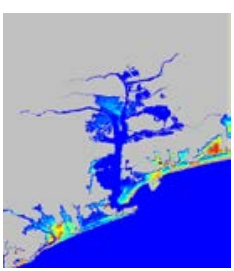

(b) Damage $50 \%$

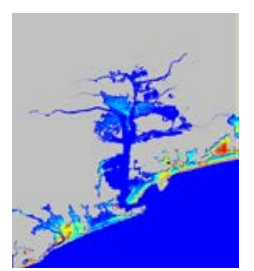

(c) Damage 100\%
Figure-2. Maximum inundation depth distribution

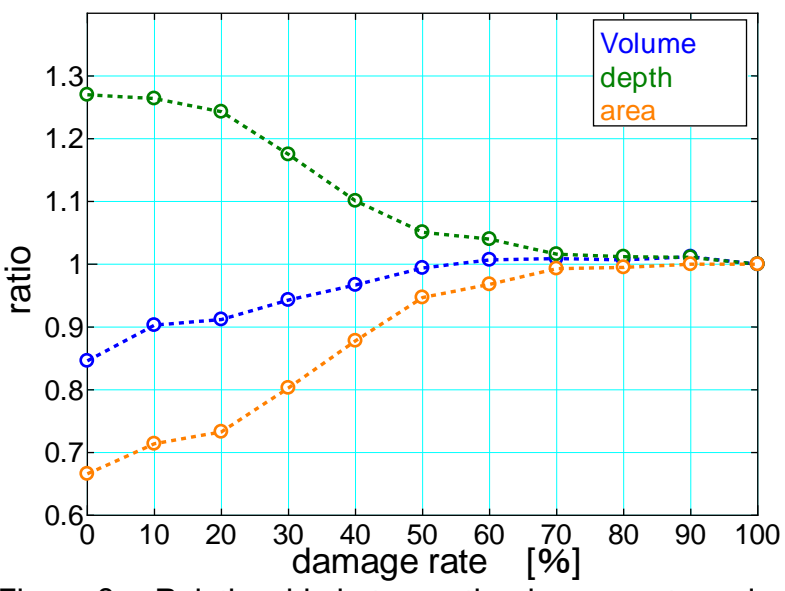

Figure-3. Relationship between the damage rate and inundation situation 